\title{
AVALIAÇÃO POR TOMOGRAFIA COMPUTADORIZADA DO ENVOLVIMENTO LOCO-REGIONAL DO CARCINOMA ESPINOCELULAR DE CORDA VOCAL*
}

\author{
Roberto Guido Santos Paiva1, Ricardo Pires de Souza², Abrão Rapoport ${ }^{3}$ Aldemir \\ Humberto Soares ${ }^{4}$
}

Resumo No período de 1992 a 1998, foram avaliados, retrospectivamente, exames de tomografia computadorizada e prontuários de 22 pacientes com carcinoma espinocelular de corda vocal. Avaliou-se a concordância entre observadores para todos os casos e a acurácia e concordância entre os métodos para os casos operados, utilizando-se o índice kappa. A concordância foi excelente para o comprometimento tumoral das cartilagens tireóide, cricóide, extensão extralaríngea e estadiamento linfonodal; ótima para o envolvimento tumoral das cordas vocais, comissura posterior e espaço paraglótico; boa para o envolvimento tumoral da supraglote, subglote e estadiamento tumoral; regular para o envolvimento tumoral da comissura anterior e cartilagem aritenóide. A utilização simultânea da avaliação clínica e tomográfica para o estadiamento T obteve acurácia e concordância com achados patológicos de $89,47 \%$ e $84,9 \%$, respectivamente, sendo superior à análise clínica isolada ou tomográfica. A acurácia e concordância patológica da tomografia computadorizada para o estadiamento $\mathbf{N}$ foi de $\mathbf{1 0 0} \%$, sendo superior à avaliação clínica.

Unitermos: Carcinoma espinocelular. Corda vocal. Tomografia computadorizada.

\begin{abstract}
Computed tomography evaluation of loco-regional involvement of squamous cell carcinoma of the vocal cord. We reviewed the case notes and computed tomography scans of 22 patients with squamous cell carcinoma of the vocal cord, in the period between 1992 and 1998. Interobserver concordance for all cases and accuracy and concordance between the methods for the operated patients were evaluated using the kappa test. Concordance was classified as follows: excellent for evaluating tumoral involvement of the thyroid and cricoid cartilages, extralaryngeal extension and lymph node staging; very good for tumoral involvement of vocal cords, posterior commissure and paraglottic space; good for tumoral involvement of the supraglottic and subglottic regions and tumoral staging; regular for tumoral involvement of the anterior commissure and arytenoid cartilage. The combination of clinical and computed tomography evaluation for $\mathbf{T}$ staging resulted in an accuracy and concordance with the pathological results of $89.47 \%$ and $84.9 \%$, respectively, which were superior to isolated clinical or computed tomography analysis. The accuracy and pathological concordance of computed tomography for $\mathbf{N}$ staging was $100 \%$, which was superior to clinical evaluation.

Key words: Squamous cell carcinoma. Vocal cord. Computed tomography.
\end{abstract}

\section{INTRODUÇÃO}

A demonstração adequada do envolvimento loco-regional do carcinoma espinocelular (CEC) de corda vocal influencia o planejamento terapêutico e prog-

* Trabalho realizado nos Serviços de Radiologia e Cirurgia de Cabeça e Pescoço do Complexo Hospitalar Heliópolis, São Paulo, SP.

1. Médico Radiologista, Mestrando do Curso de Pós-graduação em Cirurgia de Cabeça e Pescoço do Complexo Hospitalar Heliópolis.

2. Médico Radiologista, Doutor em Medicina pela Universidade de São Paulo, Diretor do Serviço de Diagnóstico por Imagem do Complexo Hospitalar Heliópolis.

3. Livre-Docente, Cirurgião de Cabeça e Pescoço, Coordenador do Curso de Pós-graduação em Cirurgia de Cabeça e Pescoço do Complexo Hospitalar Heliópolis.

4. Médico Radiologista, Presidente do Colégio Brasileiro de Radiologia.

Endereço para correspondência: Dr. Ricardo Pires de Souza. Rua Palante, 12, City América. São Paulo, SP, 05119 060. E-mail: ricapires@ig.com.br

Aceito para publicação em 16/5/2001. nóstico dos pacientes ${ }^{(1)}$. É desejável, especialmente nestes casos, além do tratamento apropriado objetivando a cura oncológica, oferecer a capacidade de fonação e deglutição de modo razoável. A avaliação clínico-endoscópica e os métodos de imagem têm a responsabilidade de demonstrar, da forma mais precisa possível, a real extensão neoplásica, avaliando o possível comprometimento de estruturas relevantes ao planejamento terapêutico $^{(2)}$. É função do radiologista avaliar adequadamente a extensão tumoral, contribuindo com informações importantes. O comprometimento linfonodal cervical também influencia a conduta e o prognóstico dos pacientes portadores de carcinoma de corda vocal. O exame físico normalmente detecta linfonodos cervicais suspeitos na vigência de lesão avançada. Contudo, em algumas situações, como a presença de metástase em linfonodo de pequenas dimensões, o exame físico pode não fazer a suspeição. A tomografia computadorizada (TC) oferece a possibilidade de avaliar as cadeias linfonodais de acesso inadequado ao exame clínico ${ }^{(3)}$. A utilidade da TC na avaliação do carcinoma de corda vocal não depende apenas da sensibilidade, especificidade e acurácia do método, mas também da reprodutibilidade da análise entre diferentes observadores. Opiniões discordantes sobre o envolvimento de determinado sítio podem ser encontradas entre diferentes radiologistas.

A partir da relevância do tema, no que se refere às suas implicações terapêuticas, fez-se o estudo objetivando: 1 - avaliar a concordância interobservadores, 
por meio da análise de TC, na detecção do envolvimento tumoral das seguintes regiões e estruturas: corda vocal direita, corda vocal esquerda, comissura anterior, comissura posterior, supraglote, subglote, cartilagem tireóide, cartilagem cricóide, cartilagem aritenóide, espaço paraglótico, tecidos extralaríngeos, extensão tumoral (estadiamento T), envolvimento linfonodal (estadiamento N); 2 estimar a concordância dos estadiamentos $\mathrm{T}$ e $\mathrm{N}$ por intermédio de avaliação clínica e/ou TC com os achados patológicos; 3 - demonstrar a acurácia destes métodos nos estadiamentos $\mathrm{T}$ e $\mathrm{N}$.

\section{CASUÍSTICA E MÉTODO}

No período de 1992 a 1998, foram selecionados e avaliados, retrospectivamente, exames de TC e prontuários de 22 pacientes com CEC de corda vocal atendidos no Complexo Hospitalar Heliópolis, São Paulo, SP. Dois pacientes eram do sexo feminino e 20 eram do sexo masculino. A idade variou entre 38 e 79 anos, a idade média foi de 58,6 anos e a mediana foi de 60,2 anos. Dezenove pacientes tiveram tratamento cirúrgico e três foram encaminhados para tratamento radioterápico inicial. Esvaziamento linfonodal foi realizado em 15 pacientes. Do total dos casos cirúrgicos, 18 eram virgens de tratamento e um paciente tinha sido submetido a radioterapia antes da realização do procedimento cirúrgico e do exame clínico e tomográfico considerados para análise.

Os exames de TC foram realizados em aparelhos de terceira geração. Foram obtidas imagens no plano axial, com o paciente em decúbito dorsal e pescoço levemente extendido, em respiração tranqüila. Os pacientes foram orientados a não deglutir e não se mover durante a realização do exame. Foram realizados cortes de $5 \mathrm{~mm}$ de espessura e de incremento. $\mathrm{O}$ plano de corte foi paralelo às cordas vocais, determinado por um topograma prévio. Em todos os pacientes foi injetado, por via endovenosa, material de contraste iodado, na dose de 1,0 a $2,0 \mathrm{ml} / \mathrm{kg}$, com concentrações de $60 \%$ e $76 \%$.

Os exames de TC foram avaliados por dois radiologistas, individualmente, sa- bedores da existência de CEC de corda vocal, mas sem o conhecimento prévio da descrição dos exames físico, laringoscópico, cirúrgico e/ou patológico. Foram levados em consideração aspectos relacionados à extensão tumoral e envolvimento linfonodal. As lesões foram classificadas segundo o estadiamento TNM, para a extensão tumoral (T) e o envolvimento linfonodal $(\mathrm{N})$.

As regiões e estruturas avaliadas foram: cordas vocais direita e esquerda, comissura anterior, comissura posterior, supraglote, subglote, cartilagem tireóide, cartilagem cricóide, cartilagem aritenóide, espaço paraglótico, tecidos extralaríngeos. Os critérios tomográficos utilizados para demonstrar invasão das cartilagens foram: erosão (todas as cartilagens), esclerose (cartilagem aritenóide), presença de lesão externamente e internamente às cartilagens. Os critérios utilizados para a caracterização do envolvimento dos demais sítios anatômicos foram a evidência de tecido tumoral, representado por atenuação de partes moles, distorcendo a anatomia normal ou obliterando os planos adiposos. As cadeias linfonodais avaliadas foram: linfonodos submentonianos e submandibulares, linfonodos jugulares altos, linfonodos jugulares médios, linfonodos jugulares baixos, linfonodos do triângulo posterior, cadeia do nervo espinhal acessório. Os critérios utilizados para caracterizar o envolvimento linfonodal na TC foram: diâmetro superior a $10 \mathrm{~mm}$ em qualquer eixo e em todas as cadeias, presença de hipodensidade central.

Os observadores realizaram o estadiamento baseados na extensão do tumor primário $(\mathrm{T})$ e na ausência ou presença de envolvimento linfonodal (N). Para cada paciente foram estabelecidas classificações T e N clínica, tomográfica e patológica (pTN), definidas pela União Internacional Contra o Câncer, revistas em 1997. O envolvimento do espaço paraglótico foi utilizado como critério para estabelecer classificações T3 tomográfica e patológica (pT3).

Avaliou-se a concordância entre os observadores para todos os casos, pela leitura dos exames de TC. Nos casos operados, avaliou-se a concordância do estadiamento loco-regional por avaliação clínica e/ou por meio de TC, considerando a análise do observador mais experiente, com o estadiamento patológico. Para a avaliação da concordância interobservadores e para a concordância entre o estadiamento clínico e/ou pela TC e os achados patológicos foi utilizado o índice kappa (K), com os critérios de concordância mostrados no Quadro 1, assumindo-se como nível de significância o valor de 0,05 e intervalo de confiança de $95 \%{ }^{(4)}$. Calculou-se, ainda, a acurácia do estadiamento clínico e/ou por intermédio de TC.

Quadro 1 Avaliação da concordância interobservadores, de acordo com o índice kappa calculado(1).

\begin{tabular}{|l|l|}
\hline Valor do índice kappa & Concordância \\
\hline$<0,00$ & Ruim \\
$0,00-0,20$ & Fraca \\
$0,21-0,40$ & Sofrível \\
$0,41-0,60$ & Regular \\
$0,61-0,80$ & Boa \\
$0,81-0,99$ & Ótima \\
$=1,00$ & Excelente \\
\hline
\end{tabular}

\section{RESULTADOS}

\section{Concordância interobservadores}

A avaliação do comprometimento tumoral da corda vocal direita mostrou concordância de $89 \%$ (índice kappa $=0,89$; ótima), e da corda vocal esquerda, de 90,9\% (índice kappa $=0,909$; ótima). A avaliação do envolvimento da comissura anterior apresentou concordância de $58,1 \%$ (índice kappa $=0,581$; regular). $\mathrm{A}$ análise da comissura posterior mostrou concordância de 86,1\% (índice kappa = 0,861 ; ótima). A avaliação do comprometimento tumoral do espaço paraglótico mostrou concordância de $81,3 \%$ (ótima). A avaliação da supraglote apresentou concordância de $80,3 \%$ (boa). Para a subglote, a concordância foi de 80,3\% (boa). Os observadores concordaram em todos os 22 casos no que se refere ao comprometimento tumoral das cartilagens tireóide e cricóide (excelente). A avaliação do comprometimento tumoral da cartilagem aritenóide mostrou concordância de $56,0 \%$ (regular). A avaliação da extensão 
tumoral extralaríngea foi concordante em todos os casos, sendo considerada excelente (índice kappa $=1,000$ ). Os observadores também concordaram em todos os casos para a detecção do envolvimento linfonodal, sendo a concordância considerada excelente. Para o estadiamento T, a concordância foi de $63,9 \%$ (boa).

\section{Concordância e acurácia dos métodos}

\section{Estadiamento $T$}

Sete pacientes foram incorretamente estadiados pela avaliação clínica. O estadiamento clínico referente à extensão tumoral teve acurácia de $63,16 \%$ e índice kappa de 0,474. A TC estadiou incorretamente quatro pacientes, com acurácia de $78,95 \%$ e índice kappa de 0,711. A utilização simultânea dos métodos clínico e tomográfico discordou do estadiamento patológico em dois casos, sendo a acurácia de $89,47 \%$ e índice kappa de 0,849.

\section{Estadiamento $N$}

O exame clínico não detectou envolvimento linfonodal em três pacientes. Dois pacientes foram considerados como N0 quando eram pN1, e um paciente N1 era $\mathrm{pN} 2 \mathrm{c}$. $\mathrm{O}$ estadiamento clínico referente ao envolvimento linfonodal tumoral teve acurácia de $80 \%$ e índice kappa de 0,516. A TC concordou em todos os casos com a patologia, sendo a acurácia de $100 \%$ e índice kappa de 1,000 .

\section{DISCUSSÃO}

\section{Cordas vocais}

O carcinoma laríngeo torna-se detectável pela TC assim que se estende além dos limites da mucosa; lesões superficiais e a presença de artefatos de movimento dificultam a análise tomográfi-

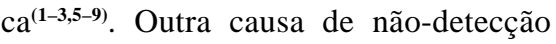
tumoral é a presença de volume parcial, em cortes de TC, obscurecendo lesões de pequenas dimensões ${ }^{(\mathbf{8})}$.

No presente estudo existiu ótima concordância interobservadores para a avaliação do envolvimento tumoral das cordas vocais, com índice kappa de 0,89 e 0,909 , respectivamente, para as cordas vocais direita e esquerda (Figura 1). Os dois casos discordantes existentes referiam-se a tumores iniciais pT1a e pT2, classificados como T0 por um dos observadores.

\section{Comissura anterior}

O carcinoma de corda vocal estendese de modo radial, com extensão submucosa em direção à comissura anterior $\mathrm{e}, \mathrm{a}$ partir deste nível, o crescimento em várias direções é facilitado. A íntima relação entre a mucosa e a cartilagem na comissura anterior facilita a extensão tumo$\mathrm{ral}^{\mathbf{( 1 0 )}}$. A comissura anterior é prontamente evidenciada na TC, possui configuração característica e é bem avaliada por este método ${ }^{(11,12)}$. O real envolvimento desta região pode não ser observado na laringoscopia ${ }^{(\mathbf{1 3})}$. A extensão tumoral profunda na comissura anterior é detectada de modo confiável pela $\mathrm{TC}^{(\mathbf{1 4})}$. A presença de edema e hemorragia pode mimetizar envolvimento da comissura anterior por tecido tumoral ${ }^{(15,16)}$.

Os observadores concordaram na detecção de envolvimento tumoral da comissura anterior em 18 pacientes (Figura 2). O índice de concordância foi regular (índice kappa =0,58). Três casos concordantes negativos demonstraram comprometimento na patologia e um caso concordante positivo não mostrava envolvimento tumoral. As maiores dificuldades na avaliação de comprometimento da comissura anterior foram a presença de lesões vegetantes projetando-se sobre a comissura e pequenos tumores superficiais comprometendo esta região, não observados na TC.

\section{Comissura posterior}

A extensão tumoral posterior no nível do processo vocal da aritenóide é relativamente incomum e o envolvimento inicial da comissura posterior é raro. Os tumores glóticos nesta região podem invadir a articulação cricoaritenóide e a submucosa do ápice do seio piriforme ${ }^{(17)}$. Os carcinomas que se originam na região aritenóide ou interaritenóide apresentam

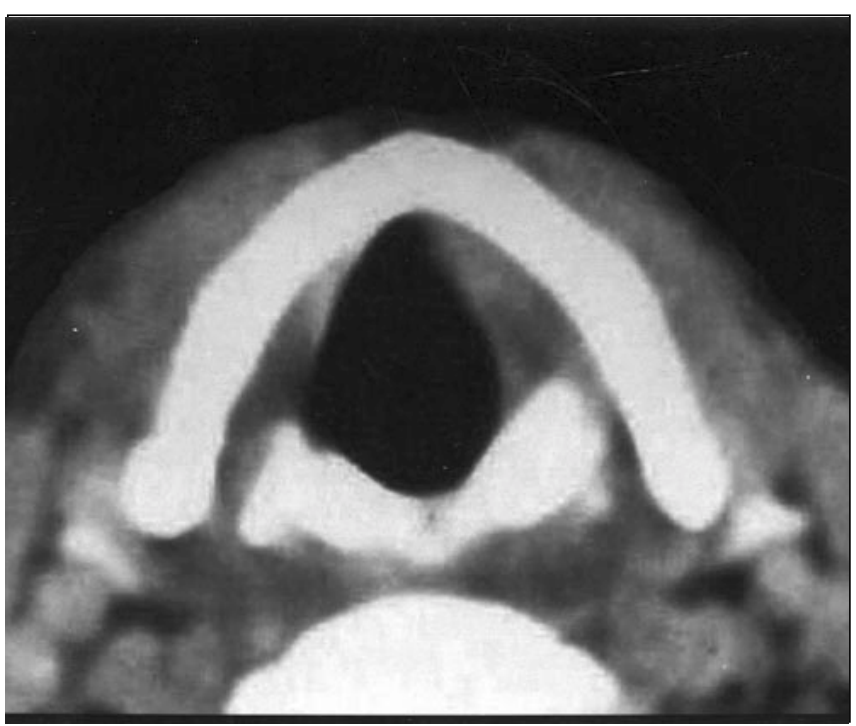

Figura 1. Corte axial de TC no nível das cordas vocais. Carcinoma espinocelular de corda vocal esquerda.

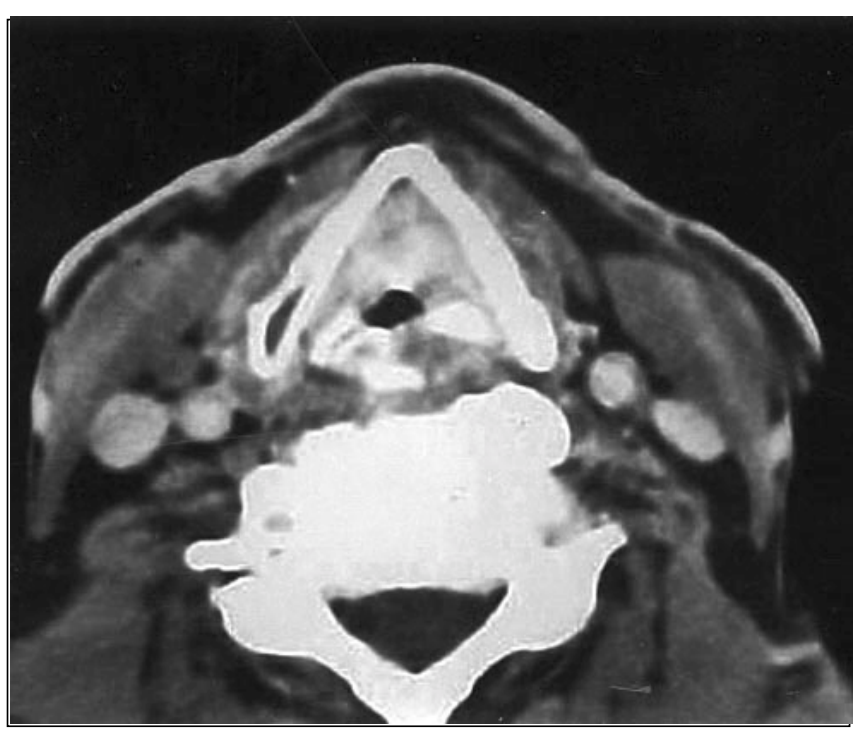

Figura 2. Corte axial de TC no nível das cordas vocais. Carcinoma espinocelular de corda vocal. Comprometimento da comissura anterior e submucoso da comissura posterior. 
tendência a estender-se de forma submu$\operatorname{cosa}^{(12)}$. A TC pode não ser confiável na existência de reações actínicas intensas nos diversos níveis analisados ${ }^{\mathbf{( 1 8 )}}$.

Nos casos do presente estudo existiu concordância interobservadores em 21 pacientes, representando concordância ótima (índice kappa $=0,86$ ). Dos quatro casos considerados como tendo comprometimento tumoral da comissura posterior, três foram comprovados na patologia. O caso não comprovado possuía espessamento tecidual relacionado a radioterapia prévia. Um paciente tinha envolvimento submucoso da região interaritenóide, não observado no exame clínico (Figura 2).

\section{Espaço paraglótico}

O espaço paraglótico (EPG) é rota importante para o crescimento tumoral longitudinal. A comunicação superior com o espaço pré-epiglótico também permite a extensão anterior ${ }^{(19)}$. O EPG é composto por músculo e tecido adiposo, e os tecidos tumoral e muscular usualmente têm a mesma densidade tomográfica, podendo ser difícil discriminar um do outro $^{(12)}$. O EPG é reconhecido na TC como uma linha hipodensa adjacente à lâmina da cartilagem tireóide e profundamente às cordas vocais, sendo geralmente simétrica, quando presente bilateralmente ${ }^{(\mathbf{1 1})}$. Esta linha pode não estar sempre presente, inclusive em indivíduos normais. Porém, quando não existir somente em um lado, contrastando com o lado normal, a infiltração do músculo tiroaritenóideo é sugerida e, possivelmente, da cartilagem tireóide $^{(20)}$. A invasão microscópica do EPG não é detectada pela TC, podendo suceder avaliação inadequada ${ }^{(21)}$. Lee $e t$ al. encontraram redução das taxas de controle local tumoral após radioterapia, na presença de envolvimento prévio do $\mathrm{EPG}^{(22)}$. Tais achados foram confirmados por Pameijer et al., particularmente quando o EPG estava comprometido no nível das bandas ventriculares ${ }^{(23)}$.

O presente estudo apresentou índice de concordância considerado ótimo para o envolvimento do espaço paraglótico (índice kappa $=0,813$ ). Os observadores concordaram em 20 pacientes (Figura 3), discordando apenas em dois casos. Um deles teve confirmação patológica de envolvimento tumoral.

\section{Supraglote}

A TC demonstra a extensão tumoral longitudinal superior e inferior de forma mais precisa que os métodos radiológicos convencionais ${ }^{(\mathbf{1 8 , 2 4 )}}$. A obtenção de múltiplos níveis para análise através de cortes axiais facilita a delimitação da extensão tumoral superior ${ }^{(25)}$.

Observou-se concordância boa para o envolvimento da supraglote, com índice kappa de 0,803 . Os avaliadores concordaram em 20 casos (Figura 3). Dos dois casos discordantes, um apresentava extensão para a supraglote, além de envol- vimento do EPG (pT3). O outro caso não possuía envolvimento, sendo uma lesão T1a. Não existiu correlação patológica em um caso concordante positivo. Tratava-se de volumosa lesão vegetante que se projetava para a supraglote, dificultando a análise tomográfica da região.

\section{Subglote}

Os métodos de imagem podem fornecer informações que contra-indicam de forma absoluta laringectomias parciais. A TC e a ressonância magnética demonstram envolvimento tumoral da subglote em imagens axiais imediatamente abaixo do plano das cordas vocais, mostrando espessamento tecidual e assimetria da coluna aérea $^{(26)}$. A subglote representa o principal sítio anatômico que deve ser avaliado nos pacientes com carcinoma glótico. A extensão tumoral para a margem superior da cricóide usualmente impossibilita a realização de hemilaringectomia. A cricóide fornece a base de sustentação laríngea, sendo a reconstrução da laringe após ressecção da cricóide inadequada $^{(27)}$. O envolvimento anterior da subglote maior que $10 \mathrm{~mm}$ e/ou posterior maior que $5 \mathrm{~mm}$ indica necessidade de laringectomia total ${ }^{(7,18,27)}$.

A avaliação do envolvimento da subglote foi considerada boa, apresentando concordância de $80,3 \%$. Os observadores concordaram em 20 pacientes (Figura 4). Treze pacientes foram concordantes positivos. Dos pacientes discordantes, ape-

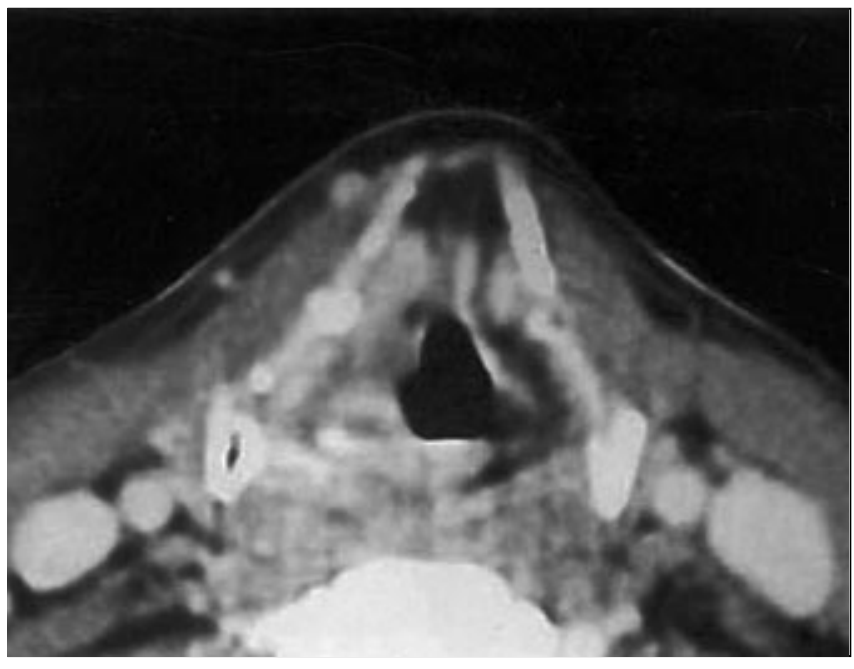

Figura 3. Corte axial de TC no nível da supraglote. Envolvimento do espaço paraglótico direito.

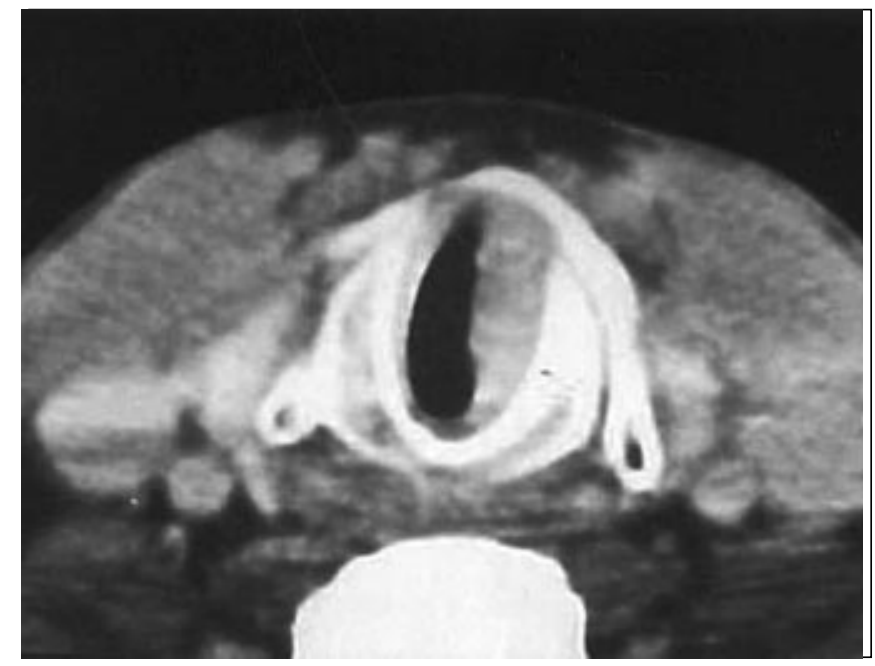

Figura 4. Corte axial de TC no nível da subglote. Presença de extensão tumoral para a subglote. 
nas um tinha comprometimento real da subglote. Dois pacientes considerados concordantes positivos não tinham extensão subglótica na patologia. Estes tinham tumores de aspecto vegetante que se projetavam inferiormente (Figura 5). Em sete pacientes a laringoscopia não conseguiu avaliar adequadamente a subglote, por causa da presença de lesões avançadas, impossibilitando a progressão apropriada do laringoscópio. A avaliação pela TC foi essencial nestes casos.

\section{Cartilagem tireóide}

Embora o envolvimento precoce seja difícil de ser identificado pela TC, a destruição grosseira da cartilagem tireóide é prontamente identificada ${ }^{(\mathbf{2 4 , 2 5 , 2 8 , 2 9 )}}$. O padrão normalmente irregular e não-uniforme de calcificação e ossificação da cartilagem tireóide faz com que seja extremamente difícil detectar o envolvimento inicial $^{(\mathbf{1 4}, \mathbf{1 6})}$. Cartilagem pouco calcificada pode ser avaliada inadequadamente pela TC, simulando erosão ou destruição ${ }^{(\mathbf{1 4}, 30)}$. O tumor pode invadir o espaço medular e não ser detectado se um número insuficiente de osso trabecular não for destruído $^{(\mathbf{1 2})}$. A erosão cartilaginosa demonstrada pela TC tem significância prognóstica, mas sua ausência não é confiável para decisões referentes a procedimentos cirúrgicos conservadores ${ }^{(25)}$.

Os observadores concordaram em todos os casos de envolvimento da cartilagem tireóide, apresentando concordân- cia considerada excelente. Os seis casos considerados comprometidos foram confirmados na patologia (Figura 6). Apesar de não ter sido relatado comprometimento cartilaginoso pela patologia nos casos concordantes negativos, a possibilidade de invasão microscópica não está descartada. Os critérios utilizados, erosão e tecido tumoral em ambos os lados da cartilagem, são muito específicos, mas carecem de sensibilidade. Este fato pode explicar a excelente concordância obtida.

\section{Cartilagem cricóide}

A avaliação da invasão da cartilagem cricóide possui resultados mais confiáveis por meio da TC do que a avaliação da cartilagem tireóide ${ }^{(\mathbf{8 , 2 8})}$.

O presente estudo evidenciou concordância interobservadores semelhante à encontrada para o envolvimento da cartilagem tireóide, inclusive em relação aos pacientes envolvidos ou não (Figura 7). As considerações sobre os critérios utilizados assemelham-se às descritas para a cartilagem tireóide.

\section{Cartilagem aritenóide}

A invasão da cartilagem aritenóide e/ou articulação cricoaritenóide limita ou mesmo exclui a possibilidade de realização de laringectomia parcial na maioria dos pacientes $^{(\mathbf{1 8 )}}$. Devido à mobilidade das cartilagens aritenóides, o deslocamento destas pelo tumor é mais freqüente que sua erosão, sendo a assimetria de posição bem demonstrada nos cortes tomográficos axiais ${ }^{(\mathbf{3 1})}$. Tumores volumosos junto à aritenóide provavelmente envolvem-na, principalmente se existir fixação ou redução da mobilidade das cordas vocais $^{(29)}$. A presença de esclerose, detectada na TC, das cartilagens cricóide e/ou aritenóide, em pacientes com câncer laríngeo, é sugestiva de comprometimento tumoral ou invasão iminente ${ }^{(32)}$.

A avaliação do comprometimento da cartilagem aritenóide apresentou concordância de $56 \%$, sendo considerada regular. Os observadores discordaram em quatro casos. Além dos critérios utilizados para as cartilagens tireóide e cricóide, foi considerada a presença ou ausência de esclerose para a caracterização de comprometimento tumoral (Figura 8).

\section{Extensão extralaríngea}

A extensão subglótica do câncer glótico maior que $1 \mathrm{~cm}$ permite extravasamento para tecidos moles através da membrana cricotireoidiana e comprometimento da glândula tireóide ${ }^{(\mathbf{1 0 , 1 7})}$. Para Becker, a invasão perilaríngea está sempre associada à destruição das margens inferior da lâmina tireoidiana e superior da cricóide ${ }^{(17)}$. Um número significativo de tumores avançados e agressivos pode extravasar para tecidos perilaríngeos e não ser facilmente palpado ${ }^{(\mathbf{1 2})}$.

Os observadores concordaram em todos os 22 casos, demonstrando extravasamento tumoral extralaríngeo em seis

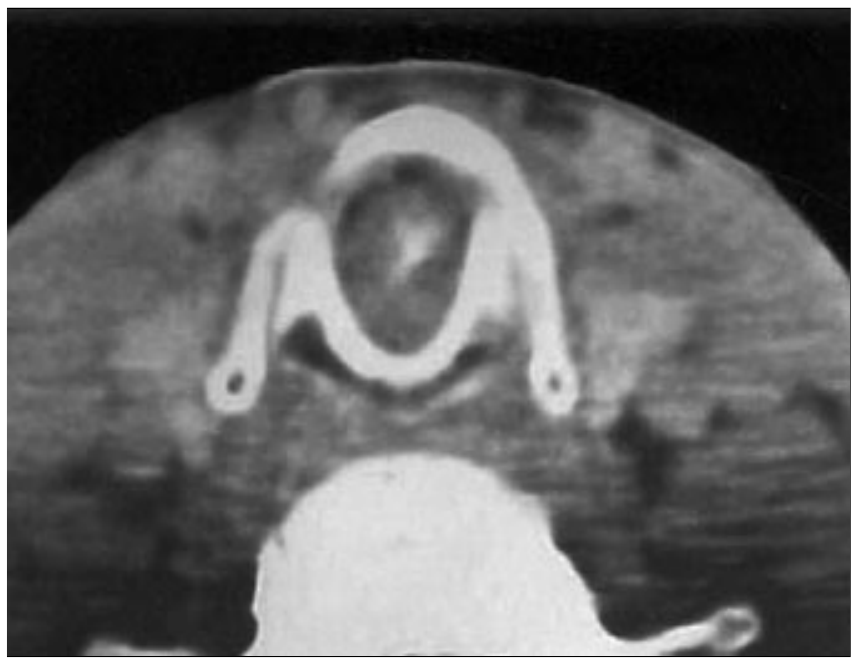

Figura 5. Corte axial de TC no nível da subglote. Lesão restrita à corda vocal projetando-se para a subglote.

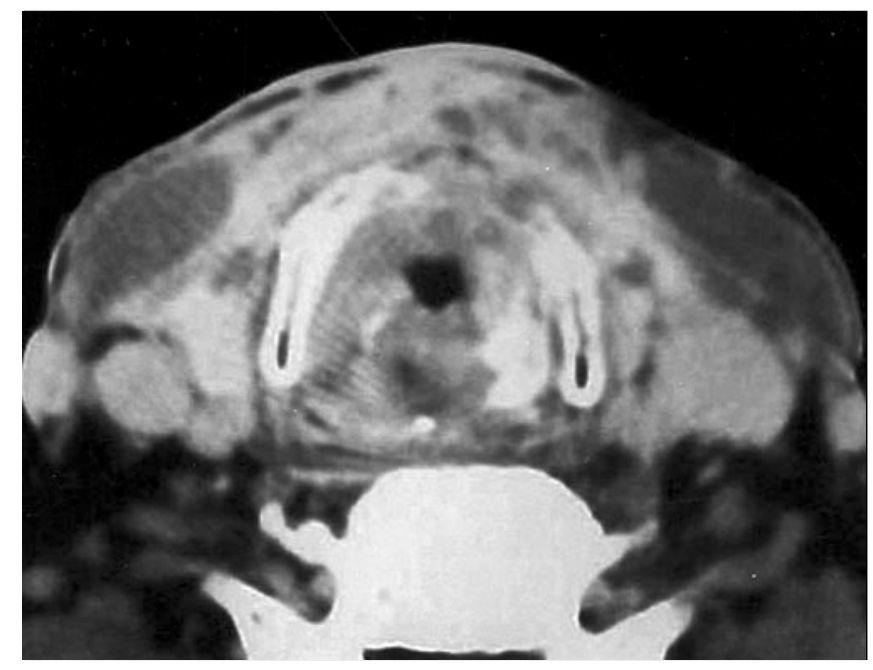

Figura 6. Corte axial de TC no nível das cordas vocais. Destruição das cartilagens tireóide e aritenóide e extensão extralaríngea. 


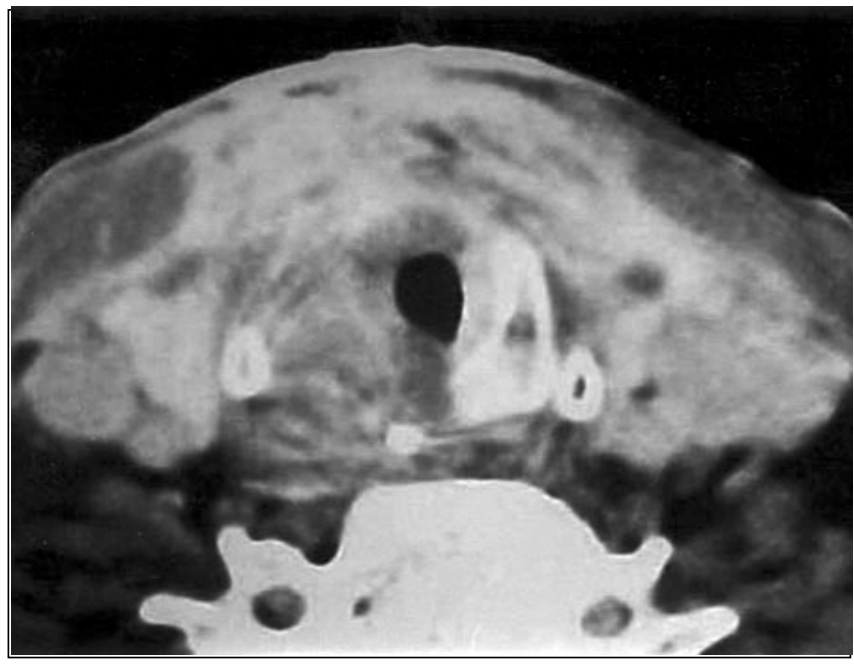

Figura 7. Corte axial de TC no nível da subglote. Destruição da cartilagem cricóide e extensão extralaríngea.

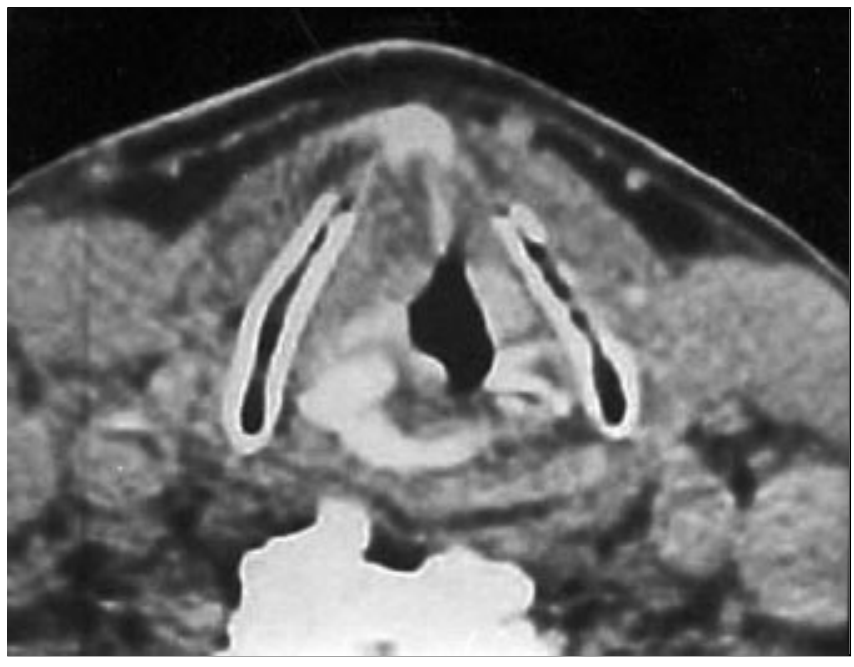

Figura 8. Corte axial de TC no nível das cordas vocais. Envolvimento tumoral da aritenóide direita, representado por esclerose. casos, e todos eles apresentavam comprometimento das cartilagens tireóide e cricóide (Figuras 6 e 7). O índice de concordância foi considerado excelente. Em um paciente existiu extensão extralaríngea detectada na cirurgia e não observada por ambos os avaliadores na análise tomográfica inicial (Figura 9).

\section{Extensão tumoral (estadiamento T)}

O estadiamento adequado do câncer de laringe é fundamental, tanto para o planejamento terapêutico apropriado como para a avaliação e comparação dos resultados obtidos com as diferentes modalidades de tratamento ${ }^{(33-35)}$. Dullerud et al. não obtiveram alterações no estadiamento de tumores glóticos classificados como T1 após o uso de $\mathrm{TC}^{(36)}$. Gerritsen et al. demonstraram, por meio de TC, envolvimento da cartilagem tireóide em dois de três tumores glóticos classificados clinicamente como $\mathrm{T} 2$, conseqüentemente alterando o estadiamento para $\mathrm{T} 4^{(37)}$. Zbaren et al. subestadiaram clinicamente 17 casos de uma casuística de 40 pacientes, dos quais 14 tinham extensão extralaríngea observada somente na TC e na patologia ${ }^{(34)}$. Kolbenstvedt et al. estudaram, retrospectivamente, 13 pacientes portadores de carcinoma glótico classificados clinicamente como tumores $\mathrm{T} 1$, não existindo alteração do estadiamento após a avaliação por $\mathrm{TC}^{(\mathbf{3 8 )}}$.

A avaliação interobservadores para o estadiamento $\mathrm{T}$ foi considerada boa (ín- dice kappa $=0,639)$. Os avaliadores concordaram em 16 pacientes. Dos seis casos discordantes, quatro referiam-se a tumores iniciais (pT1 ou pT2). Os observadores não discordaram de nenhuma lesão classificada como T4.

A análise de 19 pacientes operados no presente estudo demonstrou acurácia de $63,16 \%$ para a avaliação clínica, na classificação do estadiamento $\mathrm{T}$, e índice de concordância patológica de 0,474 . A acurácia da TC foi de 78,95\% e o índice kappa foi de 0,711. A avaliação simultânea por ambos os métodos obteve acurácia de $89,47 \%$ e índice kappa de 0,849. Um paciente estadiado como T2 foi corretamente reclassificado pela TC para T3. Quatro pacientes estadiados clinicamente como T3 foram corretamente reclassificados pela TC para T4 (Figuras 6 e 7). A tomografia classificou duas lesões como T0, sendo elas corretamente estadiadas pelo exame clínico como T1a e T2. Dois pacientes foram erroneamente estadiados por ambos os métodos. Um apresentava extravasamento extralaríngeo não identificado na TC (Figura 9) e o outro possuía volumoso tumor vegetante, restrito à corda vocal, protruindo para a supraglote e subglote (Figura 5). Nenhum paciente T1 foi reclassificado pela tomografia.

As dificuldades da TC para detectar e avaliar corretamente a extensão tumoral de pequenos tumores iniciais (T1 e T2), assim como a presença de volume parcial e artefatos de degradação, influenciaram os resultados obtidos, tanto na avaliação interobservadores como para a análise da concordância patológica e acurácia da análise tomográfica.

O exame clínico falhou no estadiamento $\mathrm{T}$ correto de tumores pT4, devido à não-identificação do comprometimento cartilaginoso e extensão extralaríngea. Cinco pacientes pT4 foram subestadiados clinicamente como T3. A TC o fez com maior precisão. Por outro lado, a TC falhou em estadiar corretamente lesões iniciais pT1 e pT2, enquanto a avaliação clínica o fez com maior exatidão. A TC não alterou o estadiamento de tumores iniciais classificados clinicamente como T1, podendo ter sido dispensável nestes casos; por outro lado, foi fundamental para a avaliação de tumores avançados pT3 e pT4. A interpretação da TC, realizada com o conhecimento prévio dos achados de exame clínico, proporcionaria avaliação mais apropriada. Devido ao exposto, o estadiamento mais adequado e o planejamento terapêutico devem ser realizados, especialmente em casos duvidosos, a partir dos achados de exames clínico, tomográfico e cirúrgico.

\section{Envolvimento linfonodal (estadiamento $\mathrm{N}$ )}

A metástase surge tardiamente no curso do carcinoma de corda vocal, por causa da drenagem linfática limitada. A extensão tumoral além dos limites da 


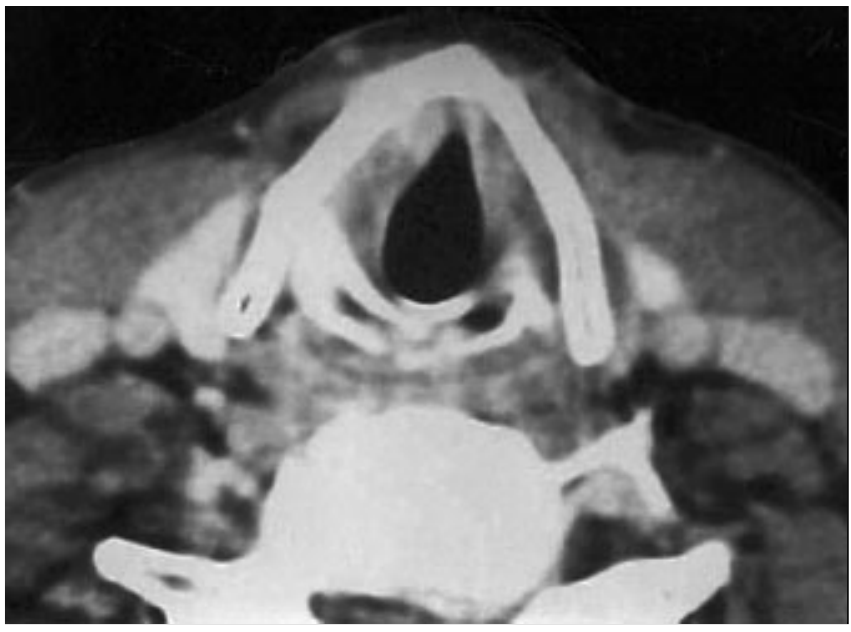

Figura 9. Corte axial de TC no nível das cordas vocais. Extensão tumoral extralaríngea à direita.

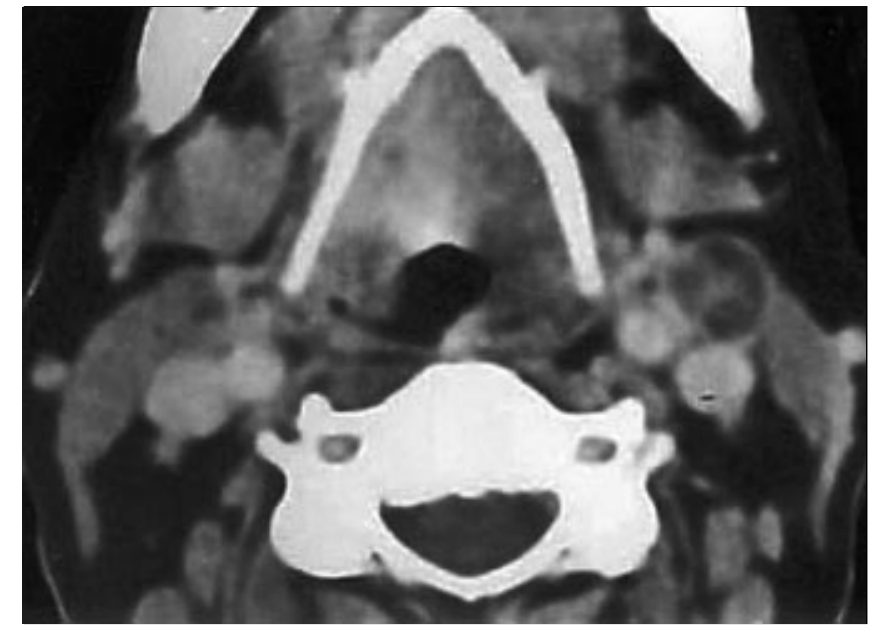

Figura 10. Corte axial de TC no nível da cadeia júgulo-carotídea alta. Metástases linfonodais bilaterais. corda vocal favorece a disseminação metastática $^{(\mathbf{1 0 )}}$. A TC pode demonstrar linfonodos não-palpáveis, mas não pode detectar se os linfonodos são metastáticos ou reacionais, exceto na existência de área evidente de necrose $\mathrm{e}^{(11,39-43)}$. Mancuso $^{(15)}$, Mancuso et al. ${ }^{(39)}$, Friedman et $a l{ }^{(43)}$ e Stevens et al. ${ }^{(42)}$ encontraram comprometimento metastático em todos os linfonodos, independentemente do tamanho, observados com hipodensidade central. $\mathrm{O}$ fato de as metástases linfonodais não serem sugeridas na TC não exclui a possibilidade de extensão linfática tumoral microscópica ${ }^{(39,42-44)}$.

No presente estudo a concordância entre os observadores foi considerada excelente para o envolvimento linfonodal. Foi observado envolvimento linfonodal em seis pacientes. Em cinco destes, obteve-se a confirmação de comprometimento metastático. Em todos os casos havia hipodensidade central (Figura 10).

A acurácia do exame clínico para a classificação do estadiamento $\mathrm{N}$ foi de $80 \%$ e o índice de concordância patológica foi de 0,516. A TC obteve acurácia de $100 \%$ e concordância patológica em todos os casos. A tomografia reclassificou o exame clínico em três casos: dois casos N0 foram reclassificados para N1 e um caso N1 foi reclassificado para N2c (Figura 10). Não existiram linfonodos considerados comprometidos ao exame clínico não observados na TC. Todos os linfonodos comprometidos apresentavam hipodensidade central. Apesar das exce- lentes acurácia e concordância obtidas por intermédio da TC, a possibilidade de comprometimento tumoral nos linfonodos não operados não pode ser afastada.

Friedman et al. encontraram acurácia de $90 \%$ para o diagnóstico de metástases linfonodais cervicais pela TC, superior ao exame clínico ${ }^{(43)}$. Stevens et al. obtiveram acurácia clínica de $70 \%$ e tomográfica de $93 \%$. A TC alterou corretamente o estadiamento linfonodal em $25 \%$ dos casos, em um total de 40 pacientes $^{(\mathbf{4 2})}$. No estudo de Sexton e Anderson a laringoscopia e a TC concordaram em $73 \%$ na demonstração de comprometimento linfonodal; porém, a TC evidenciou seis casos de prováveis linfonodopatias não detectadas clinicamente, mas não houve análise histopatológica dessas linfonodopatias. Não existiram linfonodos palpáveis não observados na $\mathrm{TC}^{(\mathbf{4 5})}$.

\section{CONCLUSÃO}

A concordância entre os observadores foi excelente para a avaliação do comprometimento tumoral das cartilagens tireóide, cricóide, extensão extralaríngea e estadiamento linfonodal; ótima para a avaliação do envolvimento tumoral das cordas vocais, comissura posterior e espaço paraglótico; boa para a avaliação do envolvimento tumoral da supraglote, subglote e estadiamento tumoral (T); e regular para a avaliação do envolvimento tumoral da comissura anterior e cartilagem aritenóide.
A utilização simultânea da avaliação clínica e pela TC para o estadiamento T do carcinoma de corda vocal forneceu a melhor concordância patológica $(84,9 \%)$ quando comparada à análise isolada clínica $(47,4 \%)$ ou tomográfica $(71,1 \%)$. A avaliação clínica apresentou concordância patológica de $51,6 \%$ para o estadiamento $\mathrm{N}$ e a $\mathrm{TC}$ concordou em todos os casos com a patologia.

A utilização simultânea da avaliação clínica e pela TC para o estadiamento T do CEC de corda vocal obteve maior acurácia $(89,47 \%)$ que a análise isolada clínica $(63,16 \%)$ ou tomográfica $(78,95 \%)$. A acurácia da TC para o estadiamento $\mathrm{N}$ foi de $100 \%$, sendo superior à clínica (80\%).

\section{REFERENCIAS}

1. Mancuso AA, Calcaterra TC, Hanafee WN. Computed tomography of the larynx. Radiol Clin North Am 1978;2:195-208.

2. Archer CR, Yeager VL. Computed tomography of laryngeal cancer with histopathological correlation. Laryngoscope 1982;92:1173-80.

3. Silverman PM, Korobkin M, Thompson WM, Johnson GA, Cole TB, Fisher SR. Work in progress: high-resolution, thin-section computed tomography of the larynx. Radiology 1982;145: 723-5.

4. Pereira MG. Epidemiologia: teórica e prática. $1^{\mathrm{a}}$ ed. Rio de Janeiro: Guanabara Koogan, 1995.

5. Feuerbach S, Gullotta U, Schmeisser KJ. Computed tomography of pharyngo-laryngeal carcinoma. Eur J Radiol 1982;2:105-8.

6. Horowitz BL, Woodson GE, Bryan RN. CT of laryngeal tumors. Radiol Clin North Am 1984; 22:265-79.

7. Reid MH. Laryngeal carcinoma: high-resolution computed tomography and thick anatomic sections. Radiology 1984;151:689-96.

8. Katsantonis GP, Archer CR, Rosenblum BN, Yeager VL, Friedman WH. The degree to which 
accuracy of preoperative staging of laryngeal carcinoma has been enhanced by computed tomography. Otolaryngol Head Neck Surg 1986;95: $52-62$

9. Charlin B, Brazeau-Lamontagne L, Guerrier B, Leduc C. Assessment of laryngeal cancer: CT scan versus endoscopy. J Otolaryngol 1989;18:283-8.

10. Batsakis JG. Tumors of the head and neck, clinical and pathological considerations. 2nd ed. Baltimore: Williams \& Wilkins, 1979.

11. Mancuso AA, Hanafee WN, Juillard GJF, Winter J, Calcaterra TC. The role of computed tomography in the management of cancer of the larynx. Radiology 1977;124:243-4.

12. Kazkayasi M, Ônder T, Kôzkaptan Y, Can C, Pabusçu Y. Comparison of preoperative computed tomographic findings with postoperative histopathological findings in laryngeal cancers. Eur Arch Otorhinolaryngol 1995;252:325-31.

13. Friedman WH, Archer CR, Yeager VL, Katsantonis GP. Computed tomography vs laryngography: a comparison of relative diagnostic value. Otolaryngol Head Neck Surg 1981;89:579-86.

14. Sagel SS, Aufderheide JF, Aronberg DJ, Stanley RJ, Archer CR. High resolution computed tomography in the staging of carcinoma of the larynx. Laryngoscope 1981;91:292-300.

15. Mancuso AA. Computed tomographic scanning of the larynx. West J Med 1979;130:445-6.

16. Silverman PM, Bossen EH, Fisher SR, Cole TB, Korobkin M, Halvorsen RA. Carcinoma of the larynx and hypopharynx: computed tomographichistopathologic correlations. Radiology 1984;151: 697-702.

17. Becker M. Larynx and hypopharynx. Radiol Clin North Am 1998;36:891-920.

18. Hoover LA, Calcaterra TC, Walter GA, Larrson SG. Preoperative CT scan evaluation for laryngeal carcinoma: correlation with pathological findings. Laryngoscope 1984;94:310-5.

19. Williams DW III. Imaging of laryngeal cancer. Otolaryngol Clin North Am 1997;30:35-58.

20. Gregor RT, Michaels L. Computed tomography of the larynx: a clinical and pathologic study. Head Neck Surg 1981;3:284-96.

21. Sulfaro S, Barzan L, Querin F, et al. T staging of the laryngohypopharyngeal carcinoma. A 7-year multidisciplinary experience. Arch Otolaryngol Head Neck Surg 1989;115:613-20.
22. Lee WR, Mancuso AA, Saleh EM, Mendenhall WM, Parsons JT, Million RR. Can pretreatment computed tomography findings predict local control in T3 squamous cell carcinoma of the glottic larynx treated with radiotherapy alone? Int J Radiat Oncol Biol Phys 1993;25:683-7.

23. Pameijer FA, Mancuso AA, Mendenhall WM, Parsons JT, Kubilis PS. Can pretreatment computed tomography predict local control in T3 squamous cell carcinoma of the glottic larynx treated with definitive radiotherapy? Int J Radiat Oncol Biol Phys 1997;37:1011-21.

24. Fraser JG, Abramovich SJ, Houang MTW. The clinical application of computed tomography in the assessment of laryngo-pharyngeal carcinoma. Preliminary report. J Laryngol Otol 1980;94:441-8.

25. Schild JA, Valvassori GE, Mafee MF, Bardawil WA. Laryngeal malignancies and computerized tomography: a correlation of tomographic and histopathologic findings. Ann Otol Rhinol Laryngol 1982;91:571-5.

26. Giron J, Joffre P, Serres-Cousine O, Senac JP. CT and MR evaluation of laryngeal carcinomas. J Otolaryngol 1993;22:284-93.

27. Curtin HD. Head and neck imaging. 3rd ed., vol. II. St. Louis: Mosby, 1996.

28. Archer CR, Sagel SS, Yeager VL, Martin S, Friedman WH. Staging of carcinoma of the larynx: comparative accuracy of CT and laryngography. AJR 1981;136:571-5.

29. Mafee MF, Schild JA, Valvassori GE, Capek V. Computed tomography of the larynx: correlation with anatomic and pathologic studies in cases of laryngeal carcinoma. Radiology 1983;147:123-8.

30. Archer CR, Friedman WH, Yeager VL, Katsantonis GP. Evaluation of laryngeal cancer by computed tomography. J Comput Assist Tomogr 1978;2: 618-24.

31. Parsons C. Computed tomography of laryngeal tumours. J Belge Radiol 1983;66:343-9.

32. Muñoz A, Ramos A, Ferrando J, et al. Laryngeal carcinoma: sclerotic appearance of the cricoid and arytenoid cartilage - CT-pathologic correlation. Radiology 1993;189:433-7.

33. Thabet HM, Sessions DG, Gado MH, Gnepp DA, Harvey JE, Talaat M. Comparison of clinical evaluation and computed tomographic diagnostic accuracy for tumors of the larynx and hypopharynx. Laryngoscope 1996;106:589-94.
34. Zbaren P, Becker M, Lang H. Pretherapeutic staging of laryngeal carcinoma: clinical findings, computed tomography, and magnetic resonance imaging compared with histopathology. Cancer 1996; 77:1263-73.

35. Zbaren P, Becker M, Lang H. Staging of laryngeal cancer: endoscopy, computed tomography and magnetic resonance versus histopathology. Eur Arch Otorhinolaryngol 1997;Suppl. 1:S117-22.

36. Dullerud R, Johansen JG, Dahl T, Faye-Lund H. Influence of CT on tumor classification of laryngeal carcinomas. Acta Radiol 1992;33:314-8.

37. Gerritsen GJ, Valk J, van Velzen DJ, Snow GB. Computed tomography: a mandatory investigational procedure for the T-staging of advanced laryngeal cancer. Clin Otolaryngol 1986;11:307-16.

38. Kolbenstvedt A, Charania B, Natvig K, Tausjo J. Computed tomography in T1 carcinoma of the larynx. Acta Radiol 1989;30:467-9.

39. Mancuso AA, Maceri D, Rice D, Hanafee W. CT of cervical lymph node cancer. AJR 1981;136:3815 .

40. Mancuso AA, Harnsberger HR, Muraki AS, Stevens $\mathrm{MH}$. Computed tomography of cervical and retropharyngeal lymph nodes: normal anatomy, variants of normal, and applications in staging head and neck cancer. Part I: normal anatomy. Radiology 1983;148:709-14.

41. Mancuso AA, Harnsberger HR, Muraki AS, Stevens MH. Computed tomography of cervical and retropharyngeal lymph nodes: normal anatomy, variants of normal, and applications in staging head and neck cancer. Part II: pathology. Radiology 1983;148:715-23.

42. Stevens MH, Harnsberger HR, Mancuso AA, Davis RK, Johnson LP, Parkin JL. Computed tomography of cervical lymph nodes. Staging and management of head and neck cancer. Arch Otolaryngol 1985;111:735-9.

43. Friedman M, Shelton VK, Mafee M, Bellity P, Grybauskas V, Skolnik E. Metastatic neck disease: evaluation by computed tomography. Arch Otolaryngol 1984;110:443-7.

44. Som PM. Lymph nodes of the neck. Radiology 1987;165:593-600.

45. Sexton CC, Anderson CG. Computed tomography in carcinoma of the larynx. Australas Radiol 1984;28:330-4. 